\title{
Physical Training and Upper-Limb Strength of People With Paraplegia: A Systematic Review
}

\author{
Flávia Cavalcante Monteiro Melo, Kátia Kamila Félix de Lima, Ana Paula Knackfuss Freitas Silveira, \\ Kesley Pablo Morais de Azevedo, Isis Kelly dos Santos, Humberto Jefferson de Medeiros, \\ José Carlos Leitão, and Maria Irany Knackfuss
}

\begin{abstract}
Context: Physical training improves the strength of upper limbs, contributing directly to the performance of activities of daily life, confirming one more time that the strengthened muscle is imperative for a rapid rehabilitation. Objective: To investigate the scientific implications of the impact of physical training on the strength of the upper limbs of people with paraplegias. Evidence Acquisition: The search strategy with truncations and Boolean operator was defined as: (spinal cord inju* OR traumatic myelopat* OR paraplegi*) AND (physical exercise OR strength training OR resisted training) AND (upper limb* OR arm OR armrest), for all of the databases. There were included experimental and quasi-experimental studies, published in the English language and with the complete text available, with at least 1 physical exercise that worked with the strength of the upper limbs. Two independent evaluators extracted from each article data on study characteristics (publishing year, country of origin, and study design), of the subjects (gender and age), and of the disability (level of lesion and cause). Evidence Synthesis: Seven articles were included in the systematic revision. The procedure used the most for measuring the maximum strength was the 1repetition maximum test, followed by the isokinetic dynamometer and Quantitative Muscle Testing System. Furthermore, the most commonly associated variables in the included studies were pain in the shoulder, cardiorespiratory capacity, and functionality, respectively. The results showed that all of the variables improved because of the training. Conclusions: The training improved the strength, the functionality, and reduced the pain in the shoulder of the people with paraplegia.
\end{abstract}

Keywords: muscle strength, disabled people, upper-extremity

\section{Context}

The World Health Organization, together with the World Bank, published the most recent World Disability Report in 2011; it showed that more than a billion people, about $15 \%$ of the world's population, had some type of disability and that $20 \%$ of those faced great difficulties in their day-to-day activities, especially in regards to functionality. ${ }^{1}$

When it comes to physical disability, regardless of it being chronic or traumatic, the diagnosis raises a number of complications, and, according to spinal segments or damaged nerve fibers, limbs or muscles will be affected immediately and permanently. ${ }^{2,3}$

The longer is the injury time, the greater are the chances of the subject becoming physically inactive and to suffer greater morphological alterations, influencing the reduction of muscle mass. ${ }^{4}$ In this regard, the people with paraplegia are taken into a cycle, in which less capacity for exercise raises the risks of the emergence of comorbidities such as the metabolic syndrome and cardiovascular diseases, mainly responsible for the death of people with paraplegia. ${ }^{5}$

In this context, research such as the one of Bortolloti and Tsukamoto $^{6}$ reveals that physical training improves the strength of

Melo, de Lima, Silveira, de Azevedo, and dos Santos are with the Graduate Program in Health and Society, Department of Nursing, Rio Grande do Norte State University, Mossoró, Brazil. de Medeiros and Knackfuss are with the Graduate Program in Health and Society, Department of Physical Education, Rio Grande do Norte State University, Mossoró, Brazil. Leitão is with the Research Center in Sports Sciences, Health Sciences and Human Development, Universidade de Tras-osMontes e Alto Douro, Vila Real, Portugal. Knackfuss (kmariairany@yahoo.com.br) is corresponding author. upper limbs, contributing directly to the performance of activities of daily life (ADL), confirming one more time that the strengthened muscle is imperative for a rapid rehabilitation.

Described as the maximum quantity of energy that a muscle or a muscle group produces in a given movement at a specific speed, strength can be classified as concentric, when muscle fibers contract and are shortened; eccentric when characterized by the stretching of the fibers in a controlled manner; and isometric when the muscle contracts generating strength without performing movement. It can be measured through the 1-repetition maximum and 10-repetition maximum tests that represents a maximum voluntary action for each number of repetitions or dynamometers. ${ }^{7}$

Taking this into consideration, muscle strength should not be underestimated, since it has direct influence on functional capacity and on the ADL, it is also a protective factor against the risk of cardiovascular diseases, the appearance of lesions, osteomyoarticular lesions and pain in the shoulder and back. ${ }^{8}$

Furthermore, it was not found that any systematic revision would approach the benefits of physical strength for the upper limbs of subjects with paraplegia, leaving a gap in the scientific research. Considering that each day this population group has been increasing in regards to their life expectancy and the need for means to live a quality lifestyle, thus, the practice of physical exercise is a proven beneficial factor.

\section{Objective}

Given the above, the objective of this study is to investigate the scientific implications of the impact of physical training on the strength of the upper limbs of people with paraplegias. 


\section{Evidence Acquisition}

\section{Search Strategy}

The search was done based on data from Web of Science, PubMed, ProQuest, and EBSCOhost on October 14 to November 14, 2015. For this, the terms used were "spinal cord injury," "traumatic myelopathy," "paraplegia," "physical exercise," "strength training," "resisted training," "upper limb," "arm," "armrest," whereas the search strategy with truncations and Boolean operator was defined as: (spinal cord inju* OR traumatic myelopat $*$ OR paraplegi*) AND (physical exercise OR strength training OR resisted training) AND (upper limb* OR arm OR armrest), for all of the databases.

\section{Selection of the Studies}

The studies were analyzed independently by 2 revisers (M.I.K. and F.C.M.M.). First, the articles were excluded based on the titles and abstracts. The full text was obtained in order to read them and to apply the inclusion and exclusion criteria. When there was a discrepancy between the selections of the 2 revisers, the opinion of a third reviser (I.K.S.) was requested.

\section{Inclusion Criteria}

Types of Studies. There were included experimental and quasiexperimental studies, published in the English language and with the complete text available, with at least 1 physical exercise that worked with the strength of the upper limbs, published starting from the beginning of the databases until November 2015. There was not any secondary search done in reference to the articles, and there was no contact with the authors of the studies.

Participants. The sample should be composed of adults with paraplegia due to the spinal cord injury, whether it is chronic or traumatic.

Types of Outcome. The articles should report which modifications occurred in the levels of strength of the upper limbs of the subjects after they were submitted for intervention.

\section{Exclusion Criteria}

The exclusion criteria were (1) descriptive studies, systematic revisions, theses, and dissertations; (2) quadriplegic subjects or victims of cerebrovascular accident; (3) training to improve gait and functional electrical stimulation; and (4) studies with animals.

\section{Data Extraction}

Two independent evaluators extracted from each article data on study characteristics (publishing year, country of origin, and study design), of the subjects (gender and age), and of the disability (level of lesion and cause), described in Table 1, having as main interest the variation of the levels of strength. The size of the sample and the main results were extracted from each study.

\section{Quality of the Evaluation}

All of the studies that were included were critically assessed using the Downs \& Black (1998) checklist. It was applied independently

Table 1 Characteristics of the Studies Included

\begin{tabular}{|c|c|c|c|c|c|c|c|c|c|}
\hline Author & Country & Design & Sample & Age, $y$ & $\begin{array}{l}\text { Level of } \\
\text { lesion }\end{array}$ & Causes & ASIA & Instrument & $\begin{array}{c}\text { Quality } \\
\text { score }\end{array}$ \\
\hline Jacobs et $\mathrm{al}^{9}$ & United States & $\mathrm{QE}$ & 10 men & $28-44$ & T5-L1 & $\begin{array}{l}\text { Chronic } \\
\text { paraplegia }\end{array}$ & - & $\begin{array}{l}\text { 1RM/Kin-Com } \\
\text { Dynamometer } \\
\text { (Isokinetic } \\
\text { International, } \\
\text { East Ridge, } \\
\text { TN) }\end{array}$ & $18 / 27$ \\
\hline Hicks et $\mathrm{al}^{10}$ & Canada & $\mathrm{RCT}$ & $\begin{array}{l}34 \text { men and }^{\text {a }} \\
\text { women }^{\mathrm{a}}\end{array}$ & $19-55$ & C4-L1 & $\begin{array}{l}\text { Traumatic spi- } \\
\text { nal cord injury }\end{array}$ & A-D & $1 \mathrm{RM}$ & $20 / 27$ \\
\hline Nash et al ${ }^{11}$ & United States & QE & 7 men & $39-58$ & T5-T12 & - & A-B & $1 \mathrm{RM}$ & $18 / 27$ \\
\hline Jacobs $^{12}$ & United States & $\mathrm{RCT}$ & $\begin{array}{l}12 \text { men and } \\
6 \text { women }\end{array}$ & $20-51$ & T6-T10 & - & - & $1 \mathrm{RM}$ & $20 / 27$ \\
\hline $\begin{array}{l}\text { Serra-Año } \\
\text { et } \mathrm{al}^{13}\end{array}$ & Spain & QE & 15 men & $26-70$ & T4-T12 & $\begin{array}{l}\text { Traumatic and } \\
\text { tumoral spinal } \\
\text { cord injury }\end{array}$ & A-B & $\begin{array}{l}\text { Dynamometer } \\
\text { Isokinetic Bio- } \\
\text { dex System } 4 \\
\text { (Biodex Medi- } \\
\text { cal Systems, } \\
\text { New York, NY) }\end{array}$ & $19 / 27$ \\
\hline $\begin{array}{l}\text { Van Straaten } \\
\text { et } \mathrm{al}^{14}\end{array}$ & United States & QE & $\begin{array}{l}13 \text { men and } \\
3 \text { women }\end{array}$ & $25-64$ & $\mathrm{~T} 2-\mathrm{C} 7$ & - & - & $\begin{array}{l}\text { Quantitative } \\
\text { Muscle Testing } \\
\text { System }\end{array}$ & $20 / 27$ \\
\hline Dost et al ${ }^{15}$ & Turkey & RCT & 19 men & $16-51$ & T5-L4 & $\begin{array}{l}\text { Traumatic and } \\
\text { firearm }\end{array}$ & $\begin{array}{l}\text { A; C; D; } \\
\text { Cauda Esquina }\end{array}$ & $\begin{array}{l}\text { Dynamometer } \\
\text { Isokinetic Bio- } \\
\text { dex Corp (Bio- } \\
\text { dex Medical } \\
\text { Systems) }\end{array}$ & $20 / 27$ \\
\hline
\end{tabular}

Abbreviations: ASIA, American Spinal Injury Association; QE, quasi-experimental; RCT, randomized clinical trial; RM, repetition maximum.

${ }^{a}$ The authors did not specify how many people belonged to which sex. 


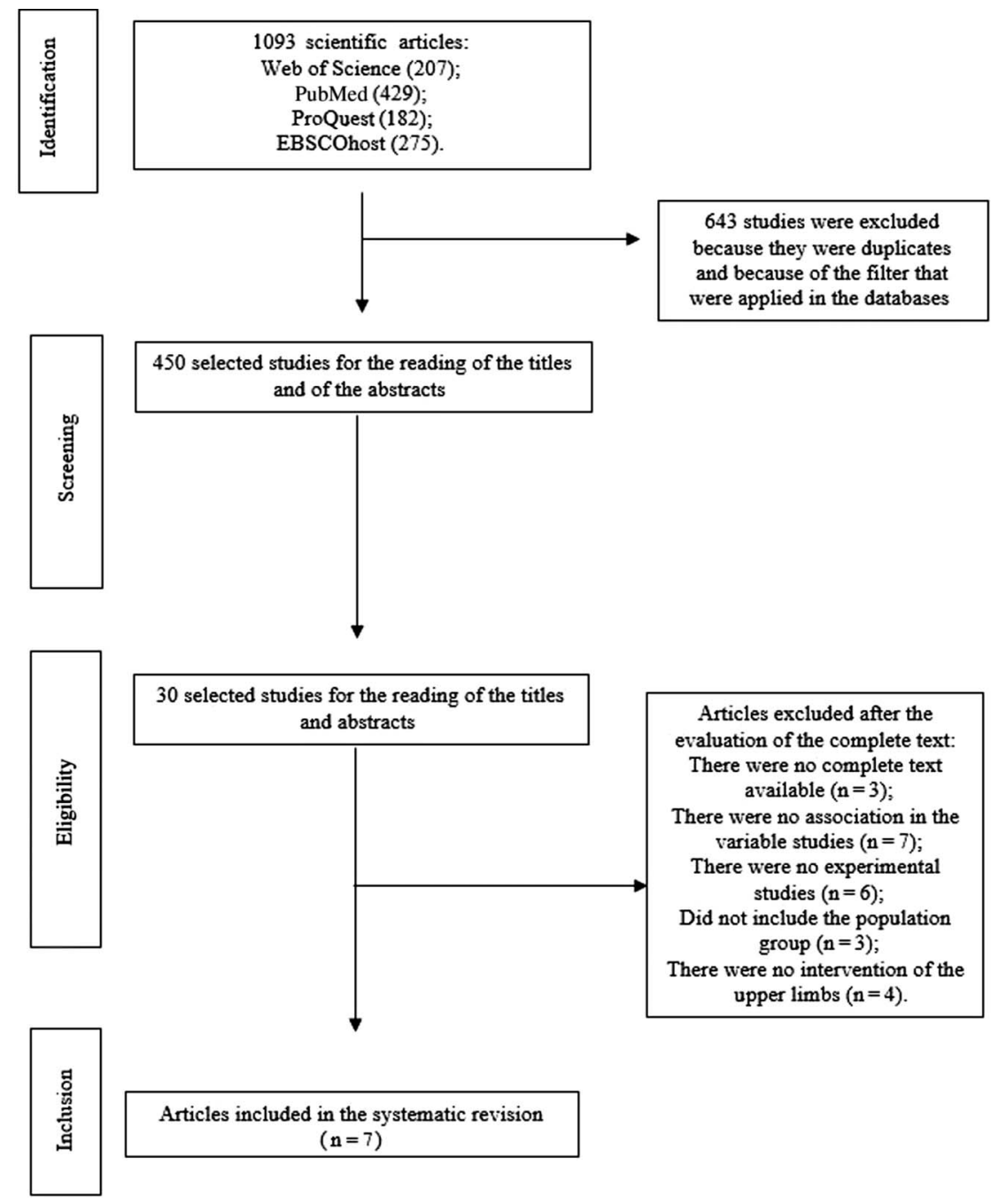

Figure 1 - Flowchart of the study phase.

by 2 revisers (M.I.K. and F.C.M.M.), and when there was divergence in the classification of the articles, a third reviser (I.K.S.) was consulted. The Preferred Reporting Items for Systematic Reviews and Meta-Analyses checklist was used, following thus the determined requisites for the elaboration of a systematic revision. The quality evaluation of the studies demonstrated that all of them presented an elevated methodological quality, with the lowest score of 18 and the highest 20 .

\section{Evidence Synthesis}

The research identified 1093 articles. Starting from the first search, there were excluded 643 articles because they were duplicates; the remaining 450 retained for the reading of the titles and of the abstract of the articles. After the reading, 420 articles were excluded because they did not meet the defined selection criteria; the remaining 30 articles were to be read completely, of those, 7 articles were included in the systematic revision (Figure 1).

\section{Characterization of the Studies}

From the 7 studies included, there were randomized clinical trials $^{10,12,15}$ and 4 were quasi-experimental papers $9,11,13,14$ published between 2001 and 2014..$^{9-15}$ Four studies were accomplished in the United States, ${ }^{9,11,12,14} 1$ in Canada, ${ }^{10} 1$ in Spain, ${ }^{13}$ and 1 in Turkey. ${ }^{15}$ The total number of participants from the 7 studies were 119 subjects, the size of the sample ranged from 7 to 34 subjects aged between 16 and 70 years of age. Three of the studies included men and women. ${ }^{10,12,14}$

The procedure used the most for measuring the maximum strength and determination of the intensity of the resistant training was the 1-repetition maximum test. It was used in 4 studies, ${ }^{10,12-14}$ 3 isokinetic dynamometer ${ }^{9,13,15}$ and 1 used the Quantitative Muscle Testing System. ${ }^{14}$ Table 1 presents a more detailed characterization of the studies.

With exception of Hicks et $\mathrm{al}^{10}$ and Dost et $\mathrm{al}^{15}$ that had 2 training sessions and 5 times per week simultaneously, the other 5 studies of this revision were accomplished in sessions 3 times a week.9,11-14 The shortest time for intervention was found in the studies of Dost et $\mathrm{al}^{15}$ where the subjects were submitted in a 5-week training, followed by 3 studies that lasted 12 weeks ${ }^{9,12,14}$ and 2 studies that extended for 16 weeks. ${ }^{11,13}$ In the studies of Hicks et al, ${ }^{10}$ we could observe a greater duration of intervention in this revision with subjects that participated in a 36-week training.

The types of training varied in the studies, in which 2 of them used exclusively the resistance training, ${ }^{10,13} 2$ others used the 
Table 2 Synthesis of the Studies Included in the Revision

\begin{tabular}{|c|c|c|c|c|c|}
\hline Author & $\begin{array}{l}\text { Type of } \\
\text { study }\end{array}$ & $\begin{array}{c}\text { Time of } \\
\text { intervention, wk }\end{array}$ & Type of intervention & Statistical analysis & Main results \\
\hline Jacobs et $\mathrm{al}^{9}$ & QE & 12 & $\begin{array}{l}40-45 \mathrm{~min} ; 3 \text { times per week; } \\
\text { ergometer cycle and strength } \\
\text { training }\end{array}$ & 1-way ANOVA & $\begin{array}{l}\text { There was an average gain of } \\
21.1 \%\end{array}$ \\
\hline Hicks et $\mathrm{al}^{10}$ & $\mathrm{RCT}$ & 36 & $\begin{array}{l}90-120 \mathrm{~min} ; 2 \text { times per week; } \\
\text { ergometer cycle and strength } \\
\text { training }\end{array}$ & $\begin{array}{l}\text { 1-way ANOVA; 2-way } \\
\text { ANOVA; Post hoc de } \\
\text { Tukey; ANCOVA }\end{array}$ & $\begin{array}{l}\text { The experimental group in- } \\
\text { creases progressively the } \\
\text { strength as it varied from } 19 \% \pm \\
34 \%\end{array}$ \\
\hline Nash et $\mathrm{al}^{11}$ & QE & 16 & $\begin{array}{l}40-45 \mathrm{~min} ; 3 \text { times per week; } \\
\text { ergometer cycle and strength } \\
\text { training }\end{array}$ & 1-way ANOVA & $\begin{array}{l}\text { Significant differences in } \\
\text { strength were observed between } \\
\text { pretraining and posttraining, } \\
\text { with an increase that varied } \\
\text { from } 38.6 \% \text { to } 59.7 \%\end{array}$ \\
\hline Jacobs $^{12}$ & $\mathrm{RCT}$ & 12 & $\begin{array}{l}3 \text { times per week; group endurance: } \\
30 \text { min of ergometer; group resis- } \\
\text { tance training: } 3 \text { sets of } 10 \text { repeti- } \\
\text { tions in } 6 \text { exercises }\end{array}$ & 2-way ANOVA & $\begin{array}{l}\text { The resistance group presented } \\
\text { gains varying from } 34 \% \text { to } \\
55 \% \text {.The endurance group did } \\
\text { not show an increase }\end{array}$ \\
\hline Serra-Añó et al ${ }^{13}$ & QE & 16 & $\begin{array}{l}3 \text { times per week; } 10 \text { min of warm- } \\
\text { up; } 3 \text { sets of } 8-12 \text { repetitions of } 8 \\
\text { different exercises }\end{array}$ & MANOVA ANOVA & $\begin{array}{l}\text { The isokinetic and isometric } \\
\text { strength of the shoulder } \\
\text { improved }\end{array}$ \\
\hline Van Straaten et $\mathrm{al}^{14}$ & QE & 12 & $\begin{array}{l}3 \text { times per week; Therabands in } \\
\text { their homes; } 3 \text { sets of } 30 \text { repetitions, } \\
30 \text { s of rest. Maintain the final } \\
\text { position for } 3 \text { s controlling the } \\
\text { eccentric phase }\end{array}$ & Wilcoxon test review & $\begin{array}{l}\text { Improvement in the isokinetic } \\
\text { strength in the anterior serractile } \\
\text { in the scapular retractors }\end{array}$ \\
\hline Dost et al ${ }^{15}$ & $\mathrm{RCT}$ & 5 & $\begin{array}{l}45 \mathrm{~min} ; 5 \mathrm{~d} / \mathrm{wk} \text {; resistance group: } 8 \\
\text { exercises, } 3 \text { sets of } 10 \text { repetitions; } \\
\text { endurance group: arm ergometer of } \\
70 \% \text { of maximum heart rate }\end{array}$ & $\begin{array}{l}\text { Mann Whitney; Wil- } \\
\text { coxon test review }\end{array}$ & $\begin{array}{l}\text { Both of the groups presented } \\
\text { gains in the isokinetics } \\
\text { parameters }\end{array}$ \\
\hline
\end{tabular}

Abbreviations: ANCOVA, analysis of covariance; ANOVA, analysis of variance; MANOVA, multivariate analysis of variance; QE, quasi-experimental; RCT, randomized clinical trial.

training in circuit (resistance training associated with an arm ergometer), ${ }^{9,11} 2$ of them used 2 interventions (one with endurance and the other with training resistance) ${ }^{12,15}$ and another one used the Theraband. ${ }^{14}$ In regards to the time for each session, there was noticed a variation of 40 to $120 \mathrm{~min},{ }^{9-11,15}$ however, in 3 studies $^{12-}$ 14 the duration of the training session was not reported. In regards to the repetition exercise, 4 studies showed that the participants accomplished 10 repetitions per exercise, ${ }^{9,11,12,15}$ one accomplished 8 to 12 repetitions, ${ }^{13}$ in another study 30 repetitions $^{14}$ and one did not have this information. ${ }^{10}$ Table 2 shows a more complete synthesis of the studies.

\section{Discussion}

This systematic review identified that physical training improves the strength of the upper limbs of people with paraplegia, as well as decreased pain, increased mobility, functionality, and improvement to perform daily activities. In this way, it is noteworthy to point out that these improvements influence the quality of life of the studied population. On the other hand, studies indicate that the improvement occurred in all maneuvers or muscle groups studied, except for the study by Hicks et al, ${ }^{10}$ where the only muscle that did not show significant statistical improvement was the anterior deltoid, which justified this result suggesting that, if the intervention program lasted longer, the result would probably be significant.

Likewise, Van Straaten et al, ${ }^{14}$ in which was made use of the Theraband in its interventions, there was significant improvement in only 2 of the 6 maneuvers that were investigated. The author divided 2 joints, the glenohumeral composed of movements of external rotation, internal rotation, plane scapular abduction and scapulothoracic joint, composed by the anterior serratus muscles and the inferior trapezium. Considering this, it was noticed that in the anterior serratus and in the scapula retractors, there was an increase in the isokinetic strength, after the utilization of many repetitions with a reduced load, which favored the decrease of pain; however, the results were not positive in regards to the levels of strength.

Gaining strength in the upper limbs was important because it positively reflects the ability to perform basic activities of daily living, in addition to moving the chair more easily, making transfers more safely, performing pressure relief lifts for longer, and conditions for day-to-day activities. ${ }^{8}$ In this way, strength training becomes a protective factor for many of the complications secondary to disability, improving functional capacity. In addition, it brings benefits to body composition and to physical fitness related to health. ${ }^{16}$

Due to the functional losses that vary as a result of the individual's level of injury and the triggering factors, it is necessary to identify the degree of dependence of the subject with respect to mobility, hygiene, feeding, among others, so that the work is directed and has the desired effects by both the professional and the evaluated. In this sense, the included studies indicate that strength training brings benefits in functionality.

On the other hand, treated with cause and effect, pain and functionality are inversely proportional magnitudes, so when there is a lot of pain, it is assumed that there is less functionality and vice versa. In order to perform the measurement, 2 studies used the 
deficiencies of arm, shoulder, and hand to follow the development of the subjects. In the study of Serra-Añó et al, ${ }^{13}$ it was observed that the scores found in the questionnaire decreased after the intervention, thus suggesting that the functionality increased. It is noteworthy that even though some individuals felt mild pain, a result different from that found by Van Straaten et al, ${ }^{14}$ where there was no observed improvement in functionality in one of the 12-week interventions with TheraBand. Nevertheless, the effect calculation was performed, showing that one of the reasons for not being significant was the reduced number of the sample.

To assess pain levels, 3 studies used the wheelchair user's shoulder pain index. All presented significant improvement in relation to preintervention and postintervention. The studies of Van Straaten et al, ${ }^{14}$ Nash et al, ${ }^{11}$ and Serra- Añó et al ${ }^{13}$ observed that the improvement was maintained even after the end of the intervention, finding significant pain in the ADL, as well as the reduction of the final scores of the questionnaire, suggesting that the pain also decreased due to the training. In relation to respiratory capacity, it can be emphasized that people with paraplegia present important changes in respiratory functions due to the occurrence of respiratory paralysis (external intercostals, diaphragm, sternocleidomastoid, scalene, lower pectoralis, and anterior serratus) or weakness of lung function, Thus, there is a facilitation of this population to present or develop pneumonia and respiratory infections. Thus, the results obtained in the Jacobs ${ }^{12}$ studies showed that there was an average peak $\mathrm{VO}_{2}$ elevation of $29.7 \%$ and, according to the author, showed that this result could have occurred in part due to the different levels of control of the upper body acquired during training. In other studies by Jacobs et al, ${ }^{9}$ it was also observed that the positive results in the groups that underwent resistance and resistance training showed improvement of $15.1 \%$ and $11.8 \%$, respectively. The authors state that the maximum $\mathrm{VO}_{2}$ values of the resistance training group are considerable, since the variable is not specifically manipulated in training.

The intervention results had various associated factors as the time of the experiment, the adherence to the training, the time of each session, the amount of times that the subject is stimulated per week, among many others. In this revision, only one study ${ }^{10}$ performed interventions twice a week, based on the theory of Taaffe et $\mathrm{al}^{17}$ in which it was affirmed that the resistance training performed once or twice a week could improve the strength of the elderly person. Based on this thought, getting a people with paraplegia to complete the training sessions twice a week becomes more convenient and feasible for them, as facing these difficulties in regards to their locomotion, without losing the benefits that it had if it was 3 times per week.

Depending on the goal that one wants to reach with the intervention, the duration is an important variable to be controlled, since some of the results are physical, physiological, or psychological, it occurs in a different manner, and an example of this is the study of Matsudo and Matsudo, ${ }^{18}$ in which they observed that in order to obtain the statistical results for the increase in bone mineral density, it was necessary to have an intervention of at least 4 months.

The physical training, independently of the modality, should be done regularly for the people in the paraplegia population group, due to the great importance of improving the capacity to perform $\mathrm{ADL}$, in the corporal composition, and motor function, already affected due to the sequelae of the disability. ${ }^{19}$

\section{Limitations of the Study}

This study has various limitations, from the methodological variations to the different instruments used to perform the evaluation.
Another important limitation factor was the selection of the studies that had only interventions of the upper limbs, considering that many of the studies done in the current scenario of the scientific research focused on the rehabilitation of the gait and in the electrical stimulation of the inferior members. The adoption of the methodological procedures were taken in order to decrease possible failure.

\section{Conclusions}

This review evaluated the available literature on physical training to improve strength of the upper limbs of people with paraplegia. The results are scarce, although some have high methodological quality. Given the available evidence, we conclude that physical training has improved strength, functionality, and reduced shoulder pain in people with paraplegia. Future research should focus on the planning and execution of long-term training and control of variables such as drug consumption, progression of load, and adherence to physical training.

\section{Acknowledgments}

The authors thank the Fundação de Apoio à Pesquisa do Rio Grande do Norte, Research Support Foundation of Rio Grande do Norte (FAPERN) and the Coordenação de Aperfeiçoamento de Pessoal de Nivel Superior, Higher Education Personnel Improvement Coordination (CAPES) for the granted Master's fellowship and to Professor José Carlos Leitão for his collaboration in all the stages of the article, as well as for the final revision of the article.

\section{References}

1. da Cruz DMC, Emmel MLG. Associação entre papeis ocupacionais, independência, tecnologia assistiva e poder aquisitivo em sujeitos com deficiência física. Rev Latino-Am Enferm. 2012;21:1-8.

2. Borges AMF, Brignol P, Schoeller SD, Bonetti A. Percepção das pessoas com lesão medular sobre a sua condição. Rev Gaúcha Enferm. 2012;33:119-125. doi:10.1590/S1983-14472012000300016

3. Sung DH, Yoon SD, Park GD. The effect of complex rehabilitation training for 12 weeks on trunk muscle function and spine deformation of patients with SCI. J Phys Ther Sci. 2015;27:951-954. PubMed ID: 25931767 doi:10.1589/jpts.27.951

4. Martin Ginis KA, Jörgensen S, Stapleton J. Exercise and sport for persons with spinal cord injury. PM R. 2012;4:894-900. PubMed ID: 23174556 doi:10.1016/j.pmrj.2012.08.006

5. van Koppenhagen CF, de Groot S, Post MW, et al. Patterns of changes in wheelchair exercise capacity after spinal cord injury. Arch Phys Med Rehabil. 2013;94:1260-1267. PubMed ID: 23510968 doi:10.1016/j.apmr.2013.02.025

6. Bortolloti LF, Tsukamoto HF. Efeitos do treinamento físico sobre a força muscular em paraplégicos. Rev Neurocienc. 2011;19(3): 462-471.

7. Stoppani J. Encyclopedia of Muscle \& Strength. Champaign, IL: Human Kinetics; 2006.

8. Sisto SA, Evans N. Activity and fitness in spinal cord injury: review and update. Curr Phys Med Rehabil Rep. 2014;2:147-157. doi:10. 1007/s40141-014-0057-y

9. Jacobs PL, Nash MS, Rusinowski JW Jr. Circuit training provides cardiorespiratory and strength benefits in persons with paraplegia. Med Sci Sports Exerc. 2001;33(5):711-717. PubMed ID: 11323537 doi:10.1097/00005768-200105000-00005

10. Hicks AL, Martin KA, Ditor DS, et al. Long-term exercise training in persons with spinal cord injury: effects on strength, arm 
ergometry performance and psychological well-being. Spinal Cord. 2003;41:34-43. PubMed ID: 12494319 doi:10.1038/sj.sc.3101389

11. Nash MS, van de Vem I, van Elk N, Johnson BM. Effects of circuit resistance training on fitness attributes and upper-extremity pain in middle-aged men with paraplegia. Arch Phys Med Rehabil. 2007;88: 70-75. PubMed ID: 17207678 doi:10.1016/j.apmr.2006.10.003

12. Jacobs PL. Effects of resistance and endurance training in persons with paraplegia. Med Sci Sports Exerc. 2009;41(5):992-997. PubMed ID: 19346989 doi:10.1249/MSS.0b013e318191757f

13. Serra-Añó P, Pellicer-Chenoll M, García-Massó X, Morales J, GinerPascual M, González LM. Effects of resistance training on strength, pain and shoulder functionality in paraplegics. Spinal Cord. 2012;50:827-831. doi:10.1038/sc.2012.32

14. Van Straaten MG, Cloud BA, Morrow MM, Ludewig PM, Zhao KD. Effectiveness of home exercise on pain, function, and strength of manual wheelchair users with spinal cord injury: a high-dose shoulder program with telerehabilitation. Arch Phys Med Rehabil. 2014;95:1810-1817.e2. PubMed ID: 24887534 doi:10.1016/j.apmr.2014.05.004
15. Dost G, Dulgeroglu D, Yildirim A, Ozgirgin N. The effects of upper extremity progressive resistance and endurance exercises in patients with spinal cord injury. J Back Musculoskelet Rehabil. 2014;27(4): 419-426. doi:10.3233/BMR-140462

16. Evans N, Wingo B, Sasso E, Hicks A, Gorgey AS, Harness E. Exercise recommendations and considerations for persons with spinal cord injury. Arch Phys Med Rehabil. 2015;96(9):1749-1750. PubMed ID: 26198424 doi:10.1016/j.apmr.2015.02.005

17. Taaffe DR, Duret C, Wheeler S, Marcus R. Once-weekly resistance exercise improves muscle strength and neuromuscular performance in older adults. J Am Geriatr Soc. 1999;47:1208-1214. PubMed ID: 10522954 doi:10.1111/j.1532-5415.1999.tb05201.x

18. Matsudo SMM, Matsudo UKR. Osteoporose e atividade física. $R$ Bras Ci e Mov. 1991;5(3):33-54.

19. American College of Sports Medicine. Resisteance exercise for persons with spinal cord injury. 2013. https://www.acsm.org/docs/ brochures/spinal-cord-injury.pdf?sfvrsn=4. Accessed November 28, 2015 . 